\title{
Drill wear monitoring based on current signals
}

\author{
Xiaoli Li ${ }^{\mathrm{a}, \mathrm{b}, *}$, S.K. Tso ${ }^{\text {a }}$ \\ a Department of Manufacturing Engineering, City University of Hong Kong, Tat Chee Ave., Kowloon, Hong Kong, China \\ ${ }^{\mathrm{b}}$ Institute of Intelligent Application, Yan Shan University, 066004 China
}

Received 9 October 1998; received in revised form 13 January 1999

\begin{abstract}
This paper presents a simple method for on-line wear state monitoring and tool replacement decision-making using spindle motor and feed motor current signals in drilling. In the paper, the effects of tool wear as well as cutting parameters on the cutting current signals are analyzed. The models on the relationship between the current signals and the cutting parameters are established under different tool wear states with a partial experimental design and regression analysis. Finally, a fuzzy classification method is used to classify the tool wear states so as to facilitate defective tool replacement at the proper time. The validity and reliability of the method are verified by experimental results. (C) 1999 Elsevier Science S.A. All rights reserved.
\end{abstract}

Keywords: Wear monitoring; Current signal; Drilling

\section{Introduction}

On-line tool wear monitoring and tool replacement at the proper time are important techniques to be developed to realize a fully automated manufacturing system, as it is necessary to prevent damage of cutting tools, machine tools and workpieces. Many researchers have looked for variable ways to detect tool wear, but a highly general and reliable on-line tool wear measurement technique has to be developed. A large variety of sensors can be used for tool condition sensing [1]. Direct measurement of tool wear using optical methods can only be applied while the tool is not in contact with the workpiece [2]. Indirect methods that rely on the relationship between tool wear and measurable signals (such as force, acoustic emission, vibration, current, etc.) to estimate the tool wear have also been extensively studied. Among the used sensors for monitoring tool condition, motor current sensing constitutes a major method. Mannan et al. [3] described the feasibility of motor power and motor current sensing for adaptive control and tool condition monitoring. Mannan and Nilsson [4] presented a method using motor current measured from the

\footnotetext{
* Corresponding author. Department of Manufacturing Engineering, City University of Hong Kong, Tat Chee Ave., Kowloon, Hong Kong, China. Tel.: +852-2788-8449; Fax: +852-2788-8423; E-mail: me150001@cityu.edu.hk
}

spindle motor and feed motor to estimate the static torque and thrust in drilling, and then to monitor the tool condition. The major advantage of using the measurement of motor current to detect any malfunction in the cutting process is that the measuring apparatus does not disturb the machining process. Moreover, it can be applied in the manufacturing environment at almost no extra cost [5].

Most of the indirect approaches have been developed for fixed cutting conditions. In practical applications, however, the cutting conditions are not fixed. The spindle and feed speed might change according to control strategies (e.g., reducing the feed before approaching corner points to avoid over cut). Therefore, a wear estimation strategy that operates under varying cutting conditions is much-needed [6].

In this paper, the currents of the spindle and feed motors are used to estimate the drill wear state. The currents depend on the cutting parameters: the cutting speed $v$, the feed rate $f$, drill diameter $d$, as well as on its wear $w$. This paper introduces a new method for on-line estimation of drill wear from the currents measured using a regression technology and a fuzzy classification method over a wide range of cutting condition. The essence of the method is to establish a simple model relating the measured current value and the drill wear state under different cutting conditions. Based on the model, the tool wear states can then be estimated from the knowledge of the cutting parameters and the motor current signals. When the 
Table 1

Experimental conditions

\begin{tabular}{ll}
\hline Tool & Tool material: high-speed steel \\
\hline Cutting conditions & spindle speed: $3.9584,5.9743,5.9376,8.67,9.0478,10.4615,13.57,13.9486,18.0956 \mathrm{~m} / \mathrm{min}$ \\
& feed rates: $0.033,0.044,0.05,0.067,0.075,01,0.15 \mathrm{~mm} / \mathrm{rev}$ \\
& drill diameters: $4.6,7.2,9.6 \mathrm{~mm}$ \\
& flank wear: $0.2,0.5,0.8 \mathrm{~mm}$ \\
& without coolant \\
Workpiece & 45\# quench steel \\
\hline
\end{tabular}

tool wear state is 'severe', the tool have to be replaced. According to the tool wear state obtained, the decision about tool replacement can be made. Experimental results show that the method can be effectively employed in practice.

\section{Effects of cutting parameters and tool wear on the current signals}

In order to establish the model of current signals as a function of the cutting parameters and tool wear, the effects of cutting parameters and tool wear on the current signals are first examined. A series of experiments carried out over a range of cutting conditions are presented. Fig. 1 shows a schematic diagram of the experimental set-up. Cutting tests were performed on a Machining Center Makino-FNC74-A20. The four axes (spindle, $X, Y$, and $Z$ ) of the machine are directly driven by permanent magnet synchronous AC servomotors. The AC servomotor current signals of the Machine Center were measured with Hall current sensors. The signals were first passed through low-pass filters (cutoff frequency: $500 \mathrm{~Hz}$ ); and then sent to a personal computer via an A/D converter. Table 1 shows the experimental cutting conditions. In these experi-

Table 2

Drilling conditions and current signals for modeling

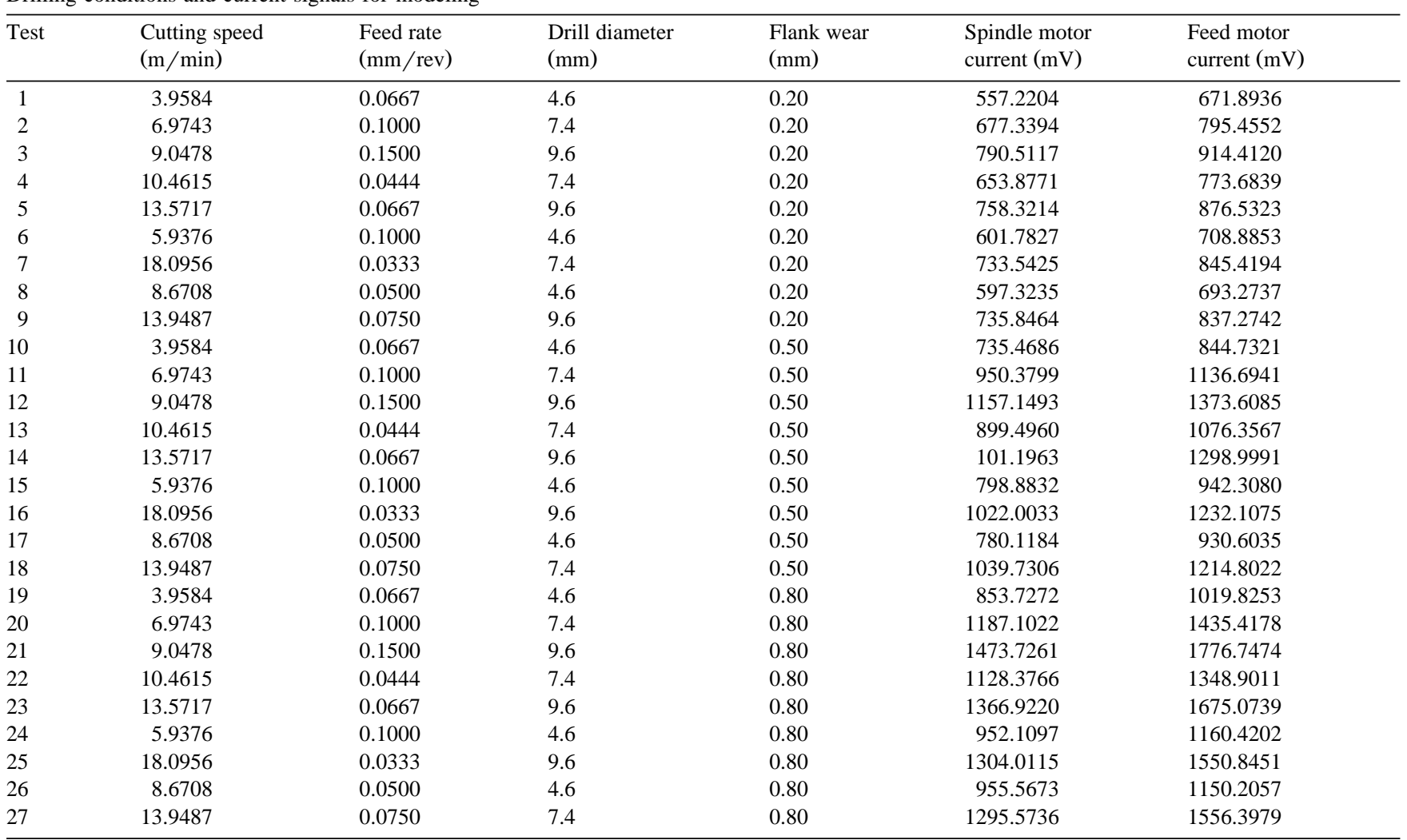




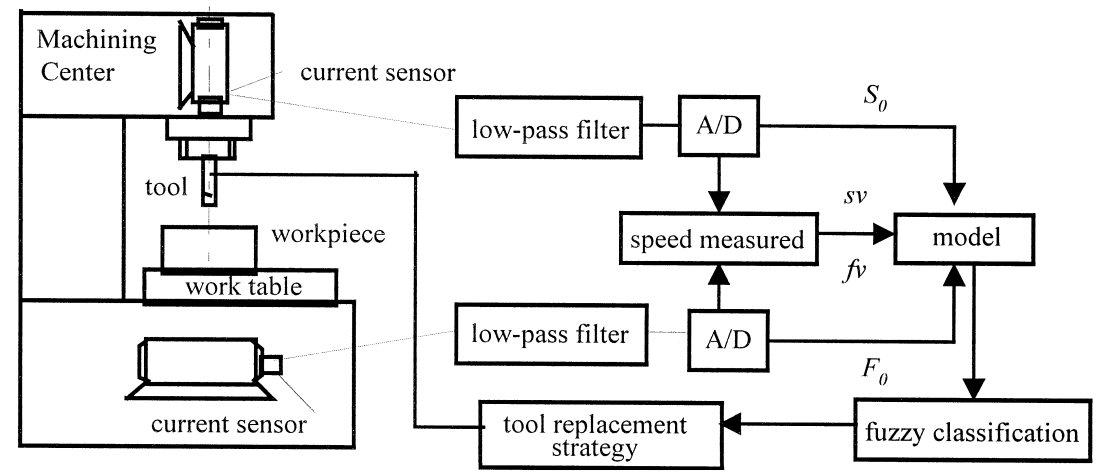

Fig. 1. A schematic diagram of the experimental set-up.

ments, the flank wear is taken as a standard for evaluating drills wear condition. The tool wear mentioned in the rest of paper refers to the drill flank wear.

The cutting parameters and the measured average current signals for each test are listed in Table 2. The current signals are measured as the $\mathrm{A} / \mathrm{D}$ converter output in millivolts $(\mathrm{mV})$.

It is generally observed that the current amplitude increases as the tool wear increases, associated with the friction between tool and workpiece. Fig. 2 shows the main effect of tool wear on the current signals. Both the spindle motor and feed motor current increase as tool wear increase, with an almost linear incremental relationship. It is found that the tool wear has more significant effects on the feed motor current than the spindle motor current.

Fig. 3 shows the main effect of the drill diameter on the current signals. It is found that both current signals increase as the drill diameter increases, with almost linear or quadratic incremental relationship obtained.

Fig. 4 shows the main effect of the spindle speed on the current signals. It is found that both current signals increase as the speed increases in the range of $0-6.0 \mathrm{~m} / \mathrm{min}$, fluctuate in the range of $6-13.6 \mathrm{~m} / \mathrm{min}$ and decrease in the range of $13.6-20 \mathrm{~m} / \mathrm{min}$. The reason for the that causes the change of current signal is complex, main influence fact is temperature, the effect of temperature is small at the low speed while the effect of temperature increase as speed increase.
Fig. 5 shows the main effect of the feed rate on the current signals. Both current signals decrease as the feed speed increases in the range of $0-0.05 \mathrm{~m} / \mathrm{min}$ and fluctuate in the range of $0.05-0.15 \mathrm{~m} / \mathrm{min}$. The reason for the condition is complex, and is discussed in Ref. [7].

Based on above studies, it is seen that the tool wear, spindle speed, feed rate, drill diameter and current signals are related. The spindle motor current and feed motor current can be selected as functions of the drill wear states, taking into account the cutting parameters. Here, the drill wear is classified into three categories: 'small', 'normal' and 'severe', with the center values given by $0.2,0.5$ and $0.8 \mathrm{~mm}$. Figs. $2-5$ are used to illustrate the relative dependencies of the various parameters and variables only. They are not directly used numerically for establishing the models.

\section{The models and test results}

\subsection{The models}

In this paper, a regression analysis is used to determine the model for the spindle motor current and feed motor current as functions of the spindle speed $v(\mathrm{~m} / \mathrm{min})$, feed rate $f(\mathrm{~mm} / \mathrm{rev})$ and drill diameter $d(\mathrm{~mm})$ when tool wear $w_{i}$ is $0.20,0.50$ and $0.80(\mathrm{~mm})$ (for $\left.i=1,2,3\right)$. The

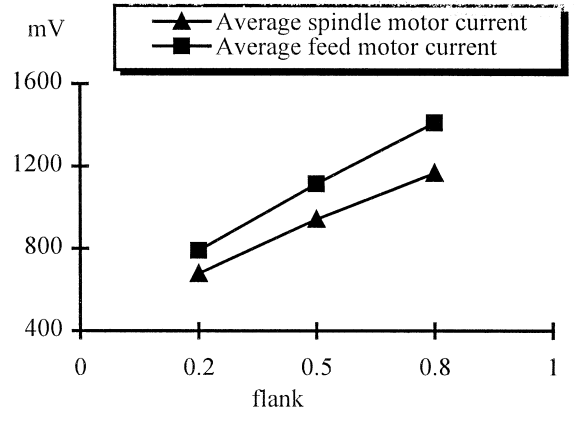

Fig. 2. The effects of flank wear on current signals.

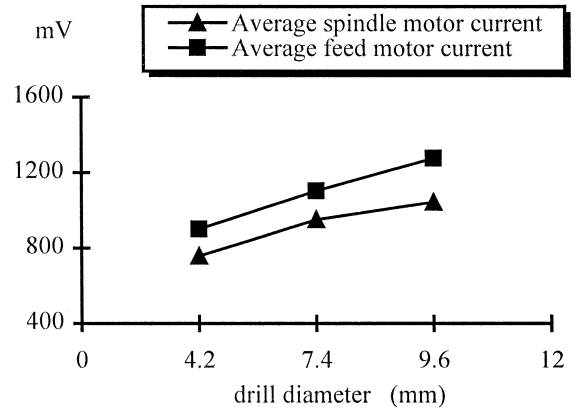

Fig. 3. The effects of drill diameter on current signals. 


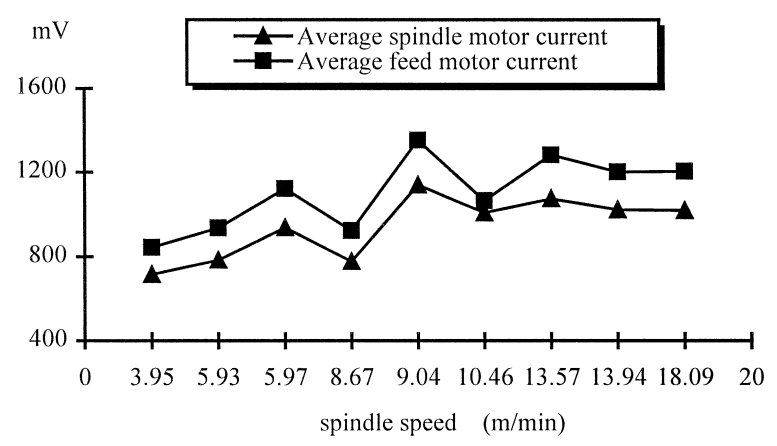

Fig. 4. The effects of spindle speed on current signals.

effect of the cutting variables $v, f$, and $d$ on the current signals, for a sharp tool, is hence assumed to be represented by the following model [8]:

$I=K_{0} v^{a_{1}} f^{a_{2}} d^{a_{3}}$

where $I$ is the current and $K_{0}$ depends on the tool geometry and workpiece material. Taking the logarithmic value of $I$, for the different tool wear values of $0.2,0.5$ and $0.8 \mathrm{~mm}$, we obtained for the spindle motor current $S_{i}$ and feed motor current $F_{i}$ (for $i=1,2,3$ ),

$S_{1}=a_{01}+a_{11} \ln v+a_{21} \ln f+a_{31} \ln d \quad w_{1}=0.2 \mathrm{~mm}$

$S_{2}=a_{02}+a_{12} \ln v+a_{22} \ln f+a_{32} \ln d \quad w_{2}=0.5 \mathrm{~mm}$

$S_{3}=a_{03}+a_{13} \ln v+a_{23} \ln f+a_{33} \ln d \quad w_{3}=0.8 \mathrm{~mm}$

$F_{1}=b_{01}+b_{11} \ln v+b_{21} \ln f+b_{31} \ln d \quad w_{1}=0.2 \mathrm{~mm}$

$F_{2}=b_{02}+b_{12} \ln v+b_{22} \ln f+b_{32} \ln d \quad w_{2}=0.5 \mathrm{~mm}$

$F_{3}=b_{03}+b_{13} \ln v+b_{23} \ln f+b_{33} \ln d \quad w_{3}=0.8 \mathrm{~mm}$

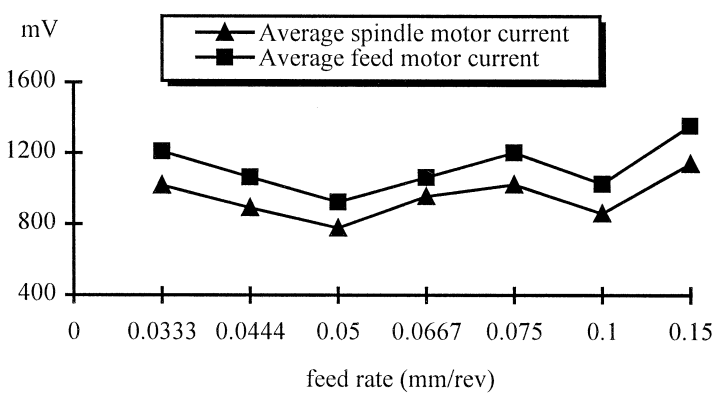

Fig. 5. The effects of feed rate on current signal.

where subscript $i=1,2,3$ denotes the respective wear values. The actual models derived from the data shown in Table 2 become

$S_{1}=2.6405+0.1502 \ln v+0.0931 \ln f+0.1807 \ln d$

$w_{1}=0.2 \mathrm{~mm}, R^{2}=0.9791$

$S_{2}=2.6884+0.1679 \ln v+0.1185 \ln f+0.3111 \ln d$

$w_{2}=0.5 \mathrm{~mm}, R^{2}=0.9911$

$S_{3}=2.7658+0.1826 \ln v+0.1536 \ln f+0.3549 \ln d$

$w_{3}=0.8 \mathrm{~mm}, R^{2}=0.9978$

$F_{1}=2.7058+0.0953 \ln v+0.0659 \ln f+0.2084 \ln d$

$w_{1}=0.2 \mathrm{~mm}, R^{2}=0.9685$

$F_{2}=2.7418+0.1828 \ln v+0.1156 \ln f+0.3136 \ln d$

$w_{2}=0.5 \mathrm{~mm}, R^{2}=0.9918$

$F_{3}=2.8641+0.1933 \ln v+0.1692 \ln f+0.3435 \ln d$

$w_{3}=0.8 \mathrm{~mm}, R^{2}=0.9986$

where $R^{2}$ is the correlation coefficient obtained in the regression analysis. It is obvious that the correlation coefficients are very close to unity, and the relationship between the current signals and the cutting parameters is reasonably well represented by the proposed models for different tool wear states.

Table 3

Drilling conditions and current signals for test cases

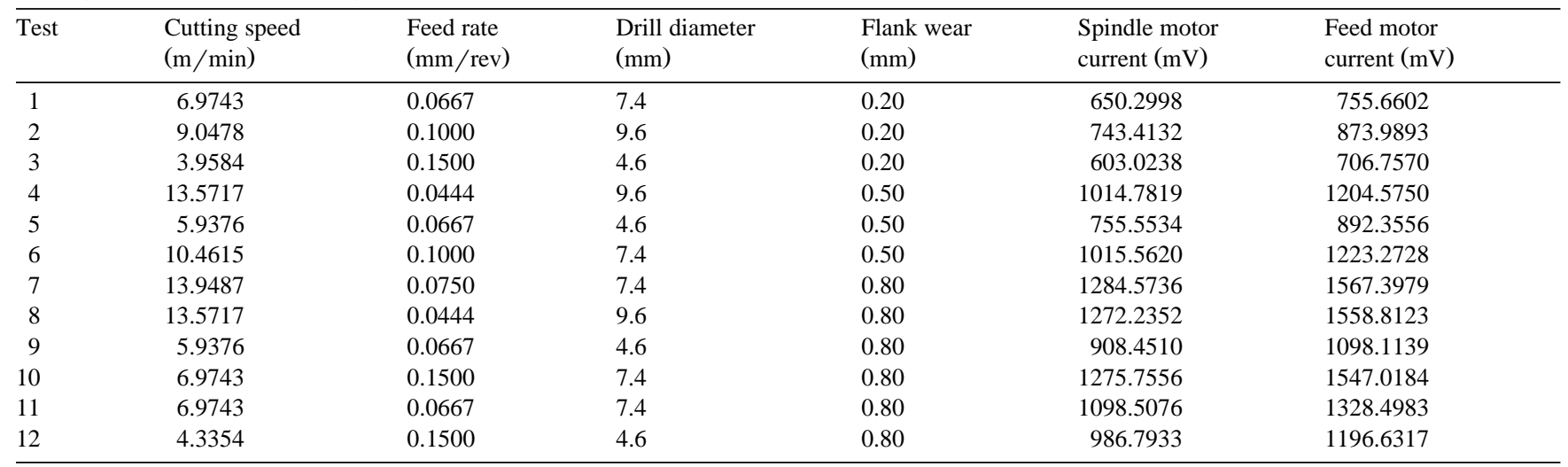


Table 4

Comparison of measured and estimated spindle motor current

\begin{tabular}{rclcr}
\hline Test & $\begin{array}{l}\text { Measured } \\
\text { current }(\mathrm{mV})\end{array}$ & $\begin{array}{l}\text { Current } \\
\text { estimated (Eq. (4.a)) }\end{array}$ & $\begin{array}{l}\text { Current } \\
\text { estimated (Eq. (4.b)) }\end{array}$ & $\begin{array}{l}\text { Current } \\
\text { estimated (Eq. (4.c)) }\end{array}$ \\
\hline 1 & 650.2998 & 652.887321 & 914.163808 & 1113.943680 \\
2 & 743.4132 & 738.944900 & 1086.469577 & 1363.073335 \\
3 & 603.0238 & 593.394516 & 789.248059 & 961.454283 \\
4 & 1014.7819 & 728.178834 & 1056.292748 & 1295.763887 \\
5 & 755.5534 & 584.830713 & 767.463080 & 914.187670 \\
6 & 1015.5620 & 720.532973 & 1026.687908 & 1276.538233 \\
7 & 1284.5736 & 732.468504 & 1041.371672 & 1287.254514 \\
8 & 1272.2352 & 728.178834 & 1056.292748 & 1295.763887 \\
9 & 908.4510 & 584.830713 & 767.463080 & 914.187670 \\
10 & 1275.7556 & 704.040134 & 1006.342942 & 1261.585462 \\
11 & 1098.5076 & 652.887321 & 914.163808 & 1113.943680 \\
12 & 986.7933 & 601.557524 & 801.396088 & 977.562191 \\
\hline
\end{tabular}

\subsection{Classification and results}

In Section 3.1, the current signal models for the different wear states (i.e., flank wear: $0.2,0.5$ and $0.8 \mathrm{~mm}$ ) are established. The models can then be used to estimate the tool wear state from measured current signals, and other cutting parameters.

Twelve additional tests were conducted to examine the feasibility of using these models to estimate the tool wear state. The drilling conditions and measured current signals for these additional tests are shown in Table 3.

Table 4 shows the comparison of the measured and estimated spindles current using Eqs. (4.a), (4.b) and (4.c), respectively. Table 5 shows the comparison of the measured and estimated feed motor current using Eqs. (5.a), (5.b) and (5.c), respectively.

The measured current and estimated current are defined as real feature values $\left(S_{0}, F_{0}\right)$ and estimated feature values $\left(S_{i}, F_{i}\right)$ (where $i=1,2,3$ ), respectively. $S_{0}, F_{0}$ are compared in turn with the estimated feature values for different defined wear states (i.e., $0.2,0.5$ and $0.8 \mathrm{~mm}$ ) in order to evaluate the degree of similarity between the real wear state to any of the estimated wear state. For the spindle motor current, the following membership $\mu_{S_{1}}$ are established:

(1) if $S_{0}<S_{i}(i=1,2,3)$ then

$\mu_{S_{1}}\left(S_{0}\right)=1, \quad \mu_{S_{2}}\left(S_{0}\right)=0, \quad \mu_{S_{3}}\left(S_{0}\right)=0$

(2) if $S_{1} \leq S_{0} \leq S_{2}$ then

$\mu_{S_{1}}\left(S_{0}\right)=\frac{S_{2}-S_{0}}{S_{2}-S_{1}}, \quad \mu_{S_{2}}\left(S_{0}\right)=\frac{S_{0}-S_{1}}{S_{2}-S_{1}}, \quad \mu_{S_{3}}\left(S_{0}\right)=0$

(3) if $S_{2} \leq S_{0} \leq S_{3}$ then

$\mu_{S_{1}}\left(S_{0}\right)=0, \quad \mu_{S_{2}}\left(S_{0}\right)=\frac{S_{3}-S_{0}}{S_{3}-S_{2}}, \quad \mu_{S_{3}}\left(S_{0}\right)=\frac{S_{0}-S_{2}}{S_{3}-S_{2}}$

(4) if $S_{0}>S_{i}(i=1,2,3)$ then

$\mu_{S_{1}}\left(S_{0}\right)=0, \quad \mu_{S_{2}}\left(S_{0}\right)=0, \quad \mu_{S_{3}}\left(S_{0}\right)=1$

where $\mu_{S_{i}}\left(S_{0}\right)$ is the membership function of $S_{0}$ associated with the $i$-th tool wear state. The same method may be used to deal with the case for the feed motor current. All the results are presented in Table 6 .

Table 5

Comparison of measured and estimated feed motor current

\begin{tabular}{rrlrl}
\hline Test & $\begin{array}{l}\text { Measured } \\
\text { current }(\mathrm{mV})\end{array}$ & $\begin{array}{l}\text { Current } \\
\text { estimated (Eq. (5.a)) }\end{array}$ & $\begin{array}{l}\text { Current } \\
\text { estimated (Eq. (5.b)) }\end{array}$ & $\begin{array}{l}\text { Current } \\
\text { estimated (Eq. (5.c)) }\end{array}$ \\
\hline 1 & 755.660200 & 775.828347 & 1078.069799 & 1338.901527 \\
2 & 873.989300 & 862.371641 & 1285.572108 & 1648.906396 \\
3 & 706.757000 & 702.264824 & 919.658279 & 1169.064528 \\
4 & 1204.575000 & 849.633130 & 1260.418562 & 1554.374341 \\
5 & 892.355600 & 691.959787 & 901.820651 & 1102.321746 \\
6 & 1223.272800 & 828.234103 & 1216.670369 & 1550.777342 \\
7 & 1567.397900 & 835.269805 & 1240.412561 & 1561.543410 \\
8 & 1558.812300 & 849.633130 & 1260.418562 & 1102.32174341 \\
9 & 1098.113900 & 691.959787 & 901.820651 & 1535.728916 \\
10 & 1547.018400 & 818.418240 & 1183.976913 & 1338.901527 \\
11 & 1328.498300 & 775.828347 & 1078.069799 & 1189.803056 \\
\hline
\end{tabular}


Table 6

Classification results

\begin{tabular}{|c|c|c|c|c|c|c|}
\hline \multirow[t]{3}{*}{ Test } & \multicolumn{6}{|c|}{ Membership values } \\
\hline & \multicolumn{3}{|c|}{ For spindle current, $\mu_{S_{i}}$} & \multicolumn{3}{|c|}{ For feed motor current, $\mu_{F_{i}}$} \\
\hline & $\overline{i=1}$ & $i=2$ & $i=3$ & $\overline{i=1}$ & $i=2$ & $i=3$ \\
\hline 1 & 0.854588 & 0.107399 & 0.038013 & 0.892022 & 0.081468 & 0.026510 \\
\hline 2 & 0.905875 & 0.071086 & 0.023039 & 0.931884 & 0.052645 & 0.015470 \\
\hline 3 & 0.769955 & 0.173926 & 0.056119 & 0.815730 & 0.147736 & 0.036534 \\
\hline 4 & 0.101055 & 0.794266 & 0.104679 & 0.080690 & 0.836412 & 0.082899 \\
\hline 5 & 0.167417 & 0.646210 & 0.186373 & 0.144955 & 0.720616 & 0.134429 \\
\hline 6 & 0.084545 & 0.810415 & 0.105039 & 0.052771 & 0.872497 & 0.074732 \\
\hline 7 & 0.027018 & 0.123010 & 0.849972 & 0.016643 & 0.077723 & 0.905633 \\
\hline 8 & 0.028250 & 0.152646 & 0.819104 & 0.017430 & 0.090273 & 0.892297 \\
\hline 9 & 0.061442 & 0.235939 & 0.702618 & 0.045310 & 0.163348 & 0.791343 \\
\hline 10 & 0.026245 & 0.107056 & 0.866699 & 0.017176 & 0.065515 & 0.917308 \\
\hline 11 & 0.038293 & 0.181595 & 0.780113 & 0.027364 & 0.118707 & 0.853929 \\
\hline 12 & 0.049318 & 0.176061 & 0.774621 & 0.034613 & 0.109647 & 0.855741 \\
\hline
\end{tabular}

The composite result is the average of the summation of the weighted membership functions:

$\mu_{c_{1}}=w_{1} \mu_{S_{i}}\left(S_{0}\right)+w_{2} \mu_{F_{i}}\left(S_{0}\right)$

where the weighting coefficient $w_{i}(i=1,2)$ satisfies the normalized condition: $w_{1}+w_{2}=1 . w_{1}, w_{2}$ reflect the relative influence of the classification result of the spindle motor current feature and the feed motor current feature, respectively. In the present system under consideration, according to above analysis, $w_{1}=0.4, w_{2}=0.6$, i.e., feed motor current feature is more important than the spindle motor current feature.

Examining these results the following conclusions can be made: the membership of the tool wear state estimated by using the above method is always very close to unity. This indicates that the method is accepted. It is shown that the flank wear state can be more accurately estimated by using the feed motor current model than by using the spindle motor current model. In other words, the feed current signal is more sensitive than the spindle motor

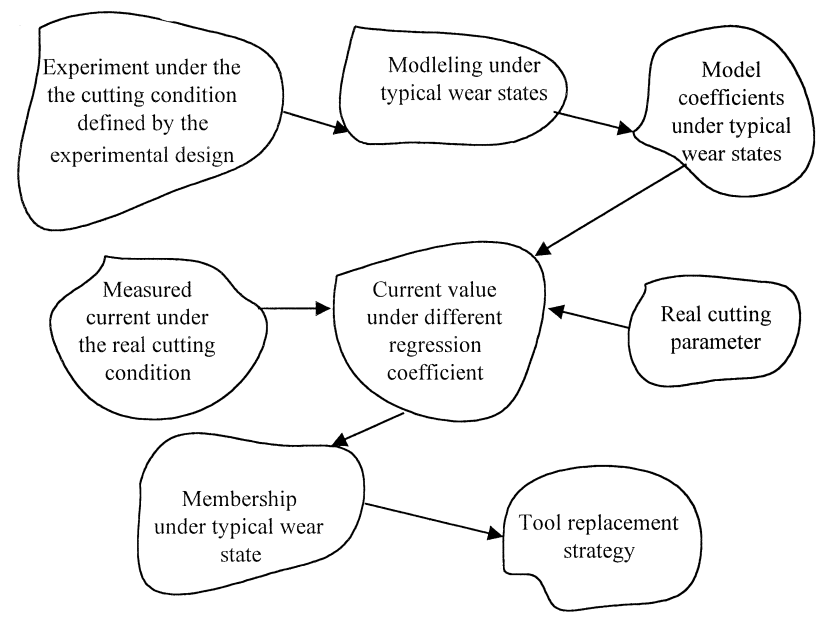

Fig. 6. A flowchart of the tool wear states recognition method. current signal to wear states. The flowchart of the tool wear states recognition method is given in Fig. 6.

\section{Cutting parameter measurement and tool replace- ment control}

\subsection{Cutting parameter measurement}

The control of tool replacement requires the recognition of the tool wear state, which is dependent on the cutting condition which may change according to the control strategies. The synchronous motor current is alternating with a frequency is proportional to the cutting speed, as shown in Fig. 7. The actual relationship as measured is governed by the following equation for the system under condition:

$\mathrm{sv}=-3.885021+22.45677 \times \mathrm{fr}_{\mathrm{s}}$

$\mathrm{fv}=0.094877+75.001874 \times \mathrm{fr}_{\mathrm{f}}$

where sv represented the spindle-rotating speed ( $\mathrm{rev} / \mathrm{min}$ ), $\mathrm{fv}$ is the feed speed $(\mathrm{mm} / \mathrm{min})$, and $\mathrm{fr}_{\mathrm{s}}\left(\mathrm{fr}_{\mathrm{f}}\right)$ is the current signal frequency of the spindle (feed) motor.

Therefore, the spindle motor and feed motor speed can be readily measured in real time by measuring the frequency of the respective current signal [9].

\subsection{Tool replacement control}

One of the main objectives of detecting the tool wear state is to obtain a basis for replacing tools. During

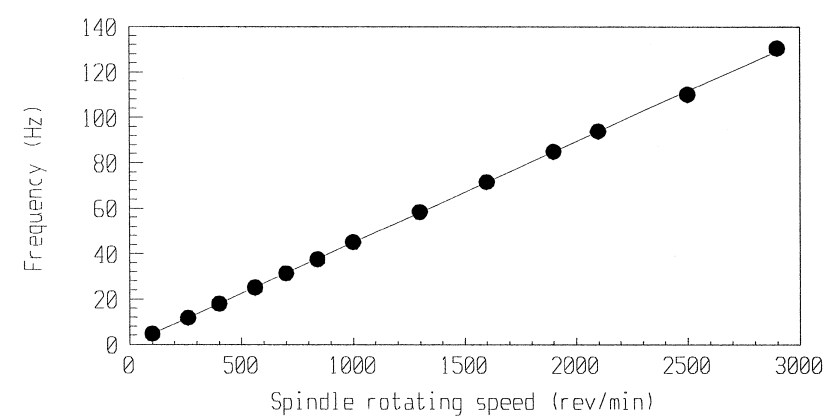

(a)

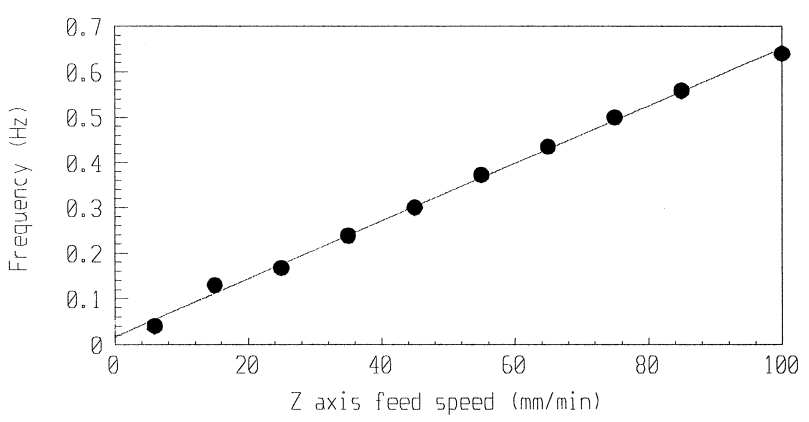

(b)

Fig. 7. The relationship between current signal frequency and speed. 
practical applications, we are interested only in noticeable changes of the tool wear states. According to the estimated tool wear state, we are able to decide if the tool should be replaced. The above method gives the tool wear state on-line according to previously collected data and test results. For the drilling operation, monitoring can be conducted by calculating the membership grade of the current observation. The tool replacement decision is made when the grade of wear in the current observation exceeds a certain threshold, say 0.8 .

For the present study, the rule for replacement is suggested as follows:

If the grade of membership $\mu_{S_{3}}$ for the spindle motor current $>0.75$ and the grade of membership $\mu_{F_{3}}$ for the feed motor current $>0.85$,

then replace the tool.

From Table 6, taking test number 8 as an example, the grades of membership from the test data are as follows: $0.028250,0.152646,0.819104 ; 0.017430,0.090273$, 0.892297 . The large values of $\mu_{S_{3}}$ and $\mu_{F_{3}}$ suggest that wear is severe and tool should be replaced.

\section{Conclusion}

(1) The effects of tool wear and cutting parameters on the spindle motor and feed motor current are analyzed. The models regarding the relationship between the current signals and the cutting parameters for different tool wear states (i.e., wear $0.2,0.5,0.8 \mathrm{~mm}$ ) are established through experimental study and regression analysis.

(2) The membership function concept has been successfully used to calculate the grade of membership for given wear states and applied to the monitoring of the drill wear state whose classification is fuzzy.

(3) The grade of membership associated with the relevant flank wear states is always very close to unity based on the established models. This indicates that the method is acceptable. It is found that the flank wear state can be more accurately estimated by using the feed motor current model than by using the spindle motor current model.

(4) The control of tool replacement requires the recognition of the tool wear state associated with the cutting parameter including the spindle speed and feed rate, which may change according to the control strategies. The paper suggests a convenient means to obtain the speeds in real time.

(5) The use of the grades of membership ( $\mu_{S_{3}}$ and $\mu_{F_{3}}$ in the paper) for the wear state provides a scientific basic for controlling the tool replacement. The method is applicable to the choice of any desired threshold of wear according to the quality standard adopted.

\section{References}

[1] L. Dan, J. Mathew, Tool wear and failure monitoring techniques for turning - a review, Int. J. Mach. Tools Manuf. 30 (4) (1990) 579-598.

[2] L.K. Daneshmand, H.A. Pak, Performance monitoring of a computer numerically controlled (CNC) lathe using pattern recognition techniques, Presented at the Third International Conference on Robot Vision and Sensor Controls, Cambridge, MA, November 6-10, 1983.

[3] M.A. Mannan, S. Broms, B. Lindustrom, Monitoring and adaptive control of cutting process by means of motor power and current measurements, Ann. CIRP 38 (1) (1989) 347-350.

[4] M.A. Mannan, T. Nilsson, The behavior of static torque and thrust due to tool wear in drilling, Technical Papers of the North American Manufacturing Research Institution of SME, 1997, 75-80.

[5] G. Byrne, D. Dornfeld, I. Inasaki, G. Ketteler, W. Konig, R. Teti, Tool condition monitoring (TCM) - the status of research and industrial application, Ann. CIRP 44 (2) (1995) 541-567.

[6] Y. Koren, T. Ko, A.G. Ulsoy, Flank wear estimation under varying cutting conditions, J. Dyn. Syst., Meas., Control. 113 (1991) 300-307.

[7] M.C. Shaw, Metal Cutting Principle, Oxford Univ. Press, Oxford, 1984.

[8] Xiaoli Li, Identification of tool wear states with fuzzy classification, Int. J. Comput. Integr. Manuf., (1999) in press.

[9] Xiaoli Li, Y. Zhejun, Machining center cutting speed detection, Manufacturing 356 (1997) 40-42. 